This item was submitted to Loughborough's Research Repository by the author.

Items in Figshare are protected by copyright, with all rights reserved, unless otherwise indicated.

\title{
Institutional, ideological and political influences on local government contracting: evidence from England
}

PLEASE CITE THE PUBLISHED VERSION

http://dx.doi.org/10.1111/padm.12216

\section{PUBLISHER}

(c) John Wiley and Sons Ltd.

\section{VERSION}

AM (Accepted Manuscript)

\section{PUBLISHER STATEMENT}

This work is made available according to the conditions of the Creative Commons Attribution-NonCommercialNoDerivatives 4.0 International (CC BY-NC-ND 4.0) licence. Full details of this licence are available at: https://creativecommons.org/licenses/by-nc-nd/4.0/

\section{LICENCE}

CC BY-NC-ND 4.0

\section{REPOSITORY RECORD}

Alonso, Jose M., Rhys Andrews, and lan Hodgkinson. 2015. "Institutional, Ideological and Political Influences on Local Government Contracting: Evidence from England". Loughborough University. https://hdl.handle.net/2134/19011. 


\title{
INSTITUTIONAL, IDEOLOGICAL AND POLITICAL INFLUENCES ON LOCAL GOVERNMENT CONTRACTING: EVIDENCE FROM ENGLAND
}

\author{
Jose M. Alonso \\ Department of Economics, University Cantabria \\ Rhys Andrews \\ Cardiff Business School, Cardiff University
}

Ian R. Hodgkinson

The School of Business and Economics, Loughborough University

Theories of contracting out offer contrasting perspectives on the noneconomic determinants of local government contracting. Some suggest ideological motives predominate, with contracting decisions reflecting the ideology of ruling parties. Others emphasise political motives, with governments responding to local preferences. In this paper, we draw on ideas about isomorphic pressures within organizational fields to examine whether institutional influences might also affect contracting behaviour. Using a spatial auto-regressive probit model, we evaluate whether mimetic pressures as well as ideological and political motives shape the decision to contract out service provision in English local governments. In addition, we analyse whether those factors also determine whether contracting local governments decide to contract with a commercial firm or a not-for-profit provider. The statistical results suggest that the decision to contract out is spatially dependent, and hence reflective of institutional forces. By contrast, political motives and market size considerations shape with whom local governments contract.

Keywords: Contracting; institutional theory; local government; ideology; politics; spatial dependence. 


\section{INTRODUCTION}

The varying commitment of public organizations to practices that policy-makers advocate is a major concern for many governments, especially those favouring privatization and service delivery innovations (Schmitt 2014; Shipan and Volden 2012). Local government contracting, in particular, is regarded as an important means to cut costs and improve the responsiveness of public services in countries across the globe (Bel and Warner 2008). Despite the on-going trend towards contracting out at the local level, not all governments contract out services to the same degree, with many preferring to retain services 'in-house'. The motivations behind the decision to contract out (or not) are thus an important area of ongoing theoretical and empirical study that can cast light on the forces that shape decisionmaking in public organizations (Baekkskov 2011). Allied to the technical, largely economic, arguments advanced in favour of contracting out, ideological and political motives have also been shown to be important determinants of externalisation (Bel and Fageda 2009). At the same time, institutional influences could shape contracting decisions, ranging from direct regulation, to wider mimetic or normative pressures to adopt successful or appropriate practices.

The policy diffusion literature has long pointed toward the role that institutional factors related to geographical proximity play in shaping public policy implementation (Money and Lee 1995; Berry and Berry 2007). In this paper, we seek to illustrate the relative importance of institutional isomorphism on public organizations by examining spatial dependence in the contracting behaviour of English local governments. First, we supplement the analysis of ideological and political influences on contracting out, with an evaluation of institutional pressures on the decision to contract out. Second, we explore whether institutional, ideological or political influences are responsible for the decision to contract with a commercial firm or a not-for-profit service provider. 
According to Di Maggio and Powell (1983), organizations are profoundly affected by the institutional forces that surround them, which lead them to adopt similar strategies, structures, and processes in order to be perceived as legitimate. These 'isomorphic' pressures take three main forms: coercive (i.e. rules and regulations), mimetic (i.e. benchmarking competition) and normative (i.e. shared values and norms). Organizations can be coerced into adopting certain practices, seek to mimic those practices that are perceived to be successful, or adopt practices that are generally regarded as "the right thing to do". Often organizations experience all three forms of isomorphic pressure (Matten and Moon 2008). For local governments, coercive pressures may come from superordinate authorities, especially higher levels of government, mimetic pressures from a desire to keep up with one’s neighbours, and normative pressures from a wider climate of received wisdom. Taken in combination, these isomorphic pressures are likely to result in governments increasingly resembling each other, especially where geographical proximity is high.

Although evidence on the ideological and political motives shaping local government contracting is gradually mounting, few studies evaluate whether institutional influences play a role in contracting decisions (e.g. Hefetz et al. 2012; Villadsen et al. 2010). Still fewer analyse spatial dependence in contracting behaviour (for a partial exception see Bivand and Szymanski 2000). Yet, research suggests local government management practices are influenced by isomorphic pressures at the field level (Ashworth et al. 2009; Villadsen 2013) and that local policy decisions are often spatially dependent (Brueckner 1998). Hence, there may be good reason to expect geographical proximity to influence contracting decisions. In this paper, we seek to address the following questions: Do pressures to adopt legitimate organizational forms influence the contracting behaviour of local governments? In particular, do governments copy the contracting practices of their neighbours? And, to what extent are 
institutional, ideological and political influences responsible for the choice of contractor, as well as the decision to contract out?

To answer these questions, we carry out statistical analysis of the contracting out of leisure services by English local governments in 2007. A spatial auto-regressive probit model is applied to secondary data on local government contracting in order to determine the relative importance of institutional, ideological and political factors on the decision to contract out and on the choice of service provider. In the following section, we explore how institutional influences might lead local governments to mimic the contracting behaviour of their neighbours, before going on to reflect on the ideological and political influences that arguably shape contracting behaviour. Thereafter, we introduce the data and methods used to carry out the study, and discuss the statistical results. We conclude the paper by considering the implications of the findings from our study.

\section{INSTITUTIONAL INFLUENCES ON LOCAL GOVERNMENT}

\section{CONTRACTING}

Classic theories of bureaucracy and public administration emphasised that due process and administrative efficiency were the key goals shaping organizational decision-making (see, for example, Gulick and Urwick 1937; Simon 1976). Building on the insights of organizational sociologists, proponents of the "new institutionalism", however, argue that the primary objective of organizational decision-making in the public (and private) sectors is not necessarily better substantive performance, but greater legitimacy in order to meet the expectations of key stakeholders in the environment (Scott 2014). Critically, new institutional theory suggests the pursuit of legitimacy is likely to encourage a tendency toward conformity across benchmarking organizations in the general operations and management practices that they adopt (Ammons and Roenigk 2015). According to Di Maggio and Powell (1983) the 
process by which this occurs can be characterised as institutional isomorphism, and is driven by coercive, mimetic and normative pressures towards homogeneity in organizations confronting similar circumstances. Coercive pressures are embedded in the rules and regulations to which organizations must submit, mimetic pressures in the best practices that diffuse throughout organizational populations, with normative pressures encapsulated in the attitudes of stakeholders regarding appropriate organizational behaviour. From this perspective, technical organizational considerations are ultimately of less importance than political ones relating to the institutional environment.

Within the local government context in England, institutional isomorphism may have been the result of the regulatory regimes that have been implemented by UK central government (Ashworth et al. 2009). Both Compulsory Competitive Tendering (CCT), advocated by the national Conservative administration in the 1990s, and Best Value, a New Labour regime of the 2000s, placed statutory obligations on local governments to consider contracting services out to external contractors. The Best Value regime, in particular, was a statutory framework for the management of local government services, which incorporated a strong expectation in favour of the outsourcing of service delivery (Ashworth et al. 2009). To ensure that local governments considered alternative modes of service provision, Best Value required them to review their functions by: challenging why and how a service is being provided; comparing performance with that of other organizations; consulting with a range of stakeholders in the setting of new performance measures; and competing for enhanced performance, by securing efficient and effective services. As such, it represents an especially apt policy context for exploring the potential salience of institutional influences on the decision-making of public organizations.

Local governments arguably operate in a competitive environment in which it is important to raise additional tax revenue by attracting residents and businesses to the local 
area (Tiebout 1956). The most straightforward, and in principle least risky, way to enhance local government tax and spending efficiency is to copy the service delivery characteristics of one’s neighbours - indeed, the policy diffusion literature has long pointed towards the propensity of governments to adopt the policies of nearby governments (see Money and Lee 1995; Berry and Berry 2007). Crucially, mimesis is a product of external institutional pressures to perform as well as internal technical ones. Villadsen (2013) argues that such mimetic institutional forces are especially likely in a horizontal peer network, where performance comparison between peers highlights performance gaps that potentially threaten the legitimacy of the organization in the eyes of key stakeholders. Local governments may therefore mimic the management practices of their neighbours to reduce the uncertainty around the implications of performance failure. In fact, comparison-of-performancebenchmarking across the sector, as promoted under the Best Value duties of challenge, compare, consult and compete, was underpinned by the threat to contract out 'failing' local services to external providers or other local authorities (Martin 2000). Thus, strong mimetic and coercive forces combined to influence the service delivery choices of English local governments during the period when Best Value was in operation.

At the same time as having strong mimetic and coercive effects, the Best Value regime also had important normative institutional effects, reflected in a 'defensive’ approach to benchmarking by local governments that was focused on the adoption of those practices most likely to be deemed legitimate, rather than those likely to improve services (Bowerman et al. 2001). This process became institutionally embedded through the formation of benchmarking clubs that enabled local governments to share and copy those approaches to service delivery that appeared to meet the external accountability demands of Best Value. In this respect a 'logic of appropriateness' could be said to have underpinned the response of English local governments to their regulatory environment as much as a 'logic of 
consequences' (Entwistle 2011). These normative pressures merged with mimetic ones, as benchmarking clubs tended to follow a pattern of geographical proximity, with lessons learned about contracting out being drawn from regional service improvement clusters.

In addition to being driven by coercive competitive effects and normative pressures, mimesis amongst public organizations is likely to be especially strong where comparable performance information is widely available and utilised by both superordinate authorities and the citizenry to hold those organizations to account. The Best Value regime was accompanied by the development of a suite of performance indicators for just this purpose. Moreover, institutional pressures towards the adoption of 'legitimate' management practices were further entrenched through the introduction of the 'Beacon Council' award scheme by UK central government at the same time as Best Value. This scheme aimed to 'recognize the best performing councils and spread best practice' (Ashworth et al. 2009: 174), and actively promoted mimesis on normative grounds. Given the confluence of coercive, mimetic and normative institutional forces surrounding English local governments during the 2000s, it seems highly likely that contracting out at that time reflected mimicry behaviour and that this behaviour was spatially dependent.

Tobler's (1970) first law of geography indicates that 'everything is related to everything else, but near things are more related than distant things', and there is good reason for anticipating that this will apply in the case of local government's decision to contract services out. Previous studies have highlighted spatial dependence in local policy decisions relating to urban growth (Brueckner 1998) and service innovations (Rincke 2006). In the face of strong institutional pressures to benchmark themselves against appropriate and successful management practices, it seems highly probable that the decision to contract out for any given local government will be influenced by the choices made by its neighbours. Not only are neighbouring governments potential competitors for mobile residents, they are also likely 
to be members of the same benchmarking and service improvement networks. Thus, where there is uncertainty about what works for service delivery, the strategic risks associated with striking a solitary path can be averted by copying one’s nearest neighbours. Nevertheless, institutional influences are not the only factors likely to shape local government decisionmaking, and we turn now to other potential noneconomic influences on contracting behaviour.

\section{IDEOLOGICAL AND POLITICAL INFLUENCES ON CONTRACTING}

The conventional motivation local governments have to contract out is the belief that this will induce cost savings. According to public choice and property rights theories (Alonso et al. 2015), contracting out enhances efficiency because it implies transferring service production away from a public sector monopoly to a scenario where multiple providers compete for business. In this scenario, as Domberger and Jensen (1997: 68) emphasise, the market "is defined by the contract specification, and the bidding process resembles an auction.” This may spur an ex-ante competition, whereby contracted services are those determined in advance to be provided at the lowest cost - something more likely to happen where there are many potential contactors (Bel and Fageda 2009). Other economic factors, such as economies of scale (Zafra-Gomez et al. 2013) and fiscal pressures (Bel and Fageda 2007, 2009) have also been suggested as drivers of contracting - though are less relevant for our analysis as during the study period English local governments benefited from central government grants that increased across the board.

In addition to economic considerations, public choice theorists point towards the importance of ideological and political influences on government contracting (Bel and Fageda 2009). As regards ideology, issues such as policy choices and politicians’ behaviour have been addressed by the public choice literature. In particular, the Citizen Candidate 
model predicts that the ideology of the ruling party is a key factor when explaining contracting out decisions: left wing parties are considered less likely to contract out while right wing parties are linked with higher levels of contracting (Osborne and Slivinski 1996). In theory, left-wing parties favour government intervention in the economy and society, whereas right-wing parties prefer the free market as a mechanism for allocating goods and services. While this idea is supported by several previous studies (e.g. Elinder and Jordahl 2013; Picazo-Tadeo et al. 2012; Sundell and Lapuente 2012), to date it has not been systematically tested in the UK, even though the local government system in the country experienced a wave of top-down reforms advocating the contracting out of public services.

Within the English context, although there has been some ideological convergence between the main left-wing (Labour) and right-wing (Conservative) parties, the similarities in the policy positions adopted by the two parties can be overstated (Smith 2010). In general, the Labour Party has continued to favour greater state involvement in the provision of public services than the Conservative Party, and during the 2000s invested large sums of public money in an effort to improve service quality. The ideological differences between Labour and the Conservative Party could therefore matter for local government contracting, because local, like national, politics continues to be dominated by these parties. These differences might also shape the choice of contractor. In particular, Labour controlled governments that 'bite the bullet' and choose to contract out may still prefer the societal ethos of a not-forprofit provider, to the commercialism of a private firm.

In terms of politics, the standard Downsian model challenges the assumption of the citizen candidate model that ideological differences generate policy divergence. From this perspective, policy choices are conditioned by the preferences of the median voter rather than the ideological pronouncements of political parties. Factors such as voters' and citizens’ preferences about the role of government are considered potentially important non-economic 
influences on the contracting out decision (see Bel and Fageda 2007, 2009). The evidence supporting the Downsian model is rather more mixed than that for the citizen candidate model, with several studies finding no evidence of political motivations for contracting out (e.g. Brudney et al. 2005; Elinder and Jordahl 2013), and a smaller number finding a connection between citizens’ attitudes and privatisation (e.g. Hefetz and Warner 2003). Nevertheless, the assumption that local governments' contracting behaviour is shaped by the demands of the median voter seems reasonable given that local government expenditures have long been found to be responsive to citizen demand (Gramlich and Rubinfeld 1982). In the case of England, the attitudes of voters towards public sector expenditures, and the state funding and provision of public services has tended to follow party political lines, with Labour voters most committed to state provision and Conservative voters least committed (Clarke et al. 2004). Labour voters are also more likely to support and belong to trade unions and professional associations that are hostile to contracting out at the local level (Foster and Scott 1998). As such, voting behaviour represents an effective means for capturing the effects of the median voter on local governments’ propensity to contract out. Thus, whatever their ideological predilections, ruling parties serving populations with a large proportion of Labour voters may be less likely to contract services out. By extension, where governments do decide to contract services out, Labour voters seem more likely to support externalisation to not-for-profit providers than the employment of commercial firms.

\section{METHODOLOGY AND DATA}

To address the question of what factors explain contracting out in English local governments, we follow a similar approach to Picazo-Tadeo et al. (2012) and deploy a sequential decisionmaking model. The model consists of series of binary choices, which implies that local governments must first choose whether or not to contract services out, before then deciding 
with whom they contract if they choose to externalise service provision. The first choice is coded in the form of an observed binary variable $\left(\mathrm{y}_{1}\right)$ taking a value of 1 if the local government decides to contract out to commercial firms or not-for-profit providers and 0 for in-house delivery. Once this decision is made, and provided that the local government decides to contract out the service $\left(\mathrm{y}_{1}=1\right)$, local governments must decide whether to sign a contract with a commercial firm or with a not-for-profit provider. This second choice is coded again as a binary variable $\left(\mathrm{y}_{2}\right)$ which takes a value of 1 if the local governments contract with commercial firms and a value of 0 when contracting with not-for-profit providers.

Following Liao (1994), this sequential model can be estimated using a series of probit models, which rely on the assumption that the probability of a given choice at each step is independent from the probability of a given choice at other steps. This should hold in our case since both variables, i.e., y1 and y2, are conceptually different - the first relates to the initial decision to contract out, while the second relates to the subsequent outcome of the contract tendering process. In addition to being conceptually distinct, y1 and y2 are statistically independent - the correlation between errors computed after standard probit estimations was not found to be different from zero. Since there may be spatial dependence among English local governments when adopting contracting out policies driven by the institutional environment in which they operate we use a Spatial Auto-Regressive (SAR) variant of the conventional probit model. The SAR model is considered as the baseline specification when the value of the dependent variable is jointly determined with that of closer spatial units (Elhorst 2009).

To overcome the potential for heteroscedasticity to bias the estimates, we adopt the Bayesian approach to estimating SAR probit models developed by LeSage (2000) and extended in Lesage and Pace (2009). This consists of a Bayesian simulation using a Markov 
Chain Monte Carlo (MCMC) method based on the Gibbs sampler. The Bayesian approach to estimating SAR probit models treats the binary observed choices in $\mathrm{y}_{1}$ and $\mathrm{y}_{2}$ as indicators of the latent utility (or profit) of the service delivery form chosen by local governments ( $\mathrm{y}_{1}{ }^{*}$ and $\left.\mathrm{y}_{2}{ }^{*}\right)$. Hence, the decision to contract out would be made when the utility of contracting versus in-house delivery is not negative. Similarly, there is another latent utility underlying the decision to sign a contract with commercial firms instead of not-for-profit providers. Like many sequential response models, we have unbalanced observations across steps, i.e., local governments who decide to keep service provision in-house at the first step are not evaluated any further, thus observations from those local governments keeping in-house delivery are dropped at the second stage. Formally, this approach can be written as:

$y_{1 i}=\left\{\begin{array}{ll}1, & \text { if } y_{1 i}^{*} \geq 0 \\ 0, & \text { if } y_{1 i}^{*}<0\end{array}\right\}$

$y_{2 i}=\left\{\begin{array}{c}1, \quad \text { if } y_{1 i}=1 \text { and } y_{2 i}^{*} \geq 0 \\ 0, \quad \text { if } y_{1 i}=1 \text { and } y_{2 i}^{*}<0 \\ \text { not evaluated if } y_{1}=0\end{array}\right\}$

This sequential model can be represented linearly as two independent equations of the following form:

$y_{1 i}^{*}=\rho_{1} \sum_{j=1}^{N_{1}} w_{i j} y_{1 j}^{*}+\beta_{1} X_{1 i}+\varepsilon_{1 i}, \quad \varepsilon_{1 i} \sim N\left(0, \sigma^{2} I_{n}\right)$

$y_{2 i}^{*}=\rho_{2} \sum_{j=1}^{N_{2}} w_{i j} y_{2 j}^{*}+\beta_{2} X_{2 i}+\varepsilon_{2 i}, \quad \varepsilon_{2 i} \sim N\left(0, \sigma^{2} I_{n}\right)$

where $y_{1 i}^{*}$ reflects the latent unobserved utility associated with contracting out, and $y_{2 i}^{*}$ the utility associated with contracting with a commercial firm rather than a not-for-profit provider in local government $i, w_{i j}$ is an element of the spatial matrix, $W$ reflecting the 
relative connectivity between local governments, $\rho$ is the spatial autoregressive coefficient, $X_{i}$ the $i$ th observation on $P$ variables explaining contracting, and $\varepsilon_{\mathrm{it}}$ the remainder disturbance term. We expect $\rho$ to be positive if mimetic institutional pressures are a relevant factor when adopting contracting out policies.

The spatial matrix $W$ is a non-negative $N \times N$ matrix, where an element $w_{i j}$ has a value greater than 0 if local governments $i$ and $j$ are connected, and 0 otherwise (local governments are not considered to be connected with themselves, thus the diagonal elements of $W$ are equal to 0). In this paper, we follow previous studies on spatial policy dependence and choose a spatial matrix based on geographical proximity, since policy dependence processes, such as mimesis or emulation, might be more likely to occur between nearby observations (Beck et al. 2006). Broadly speaking, regional policy emulation arises because policy makers and citizens more easily “analogize” to local or state governments in the same region, whether through personal experience or because neighbouring jurisdictions are more likely to share similar economic, social, and environmental circumstances (Mooney and Lee, 1995: 665; Berry and Berry, 2007). Due to this predilection for "analogization", the likelihood of a local government adopting any given policy may increase when its nearest neighbours adopt that policy. We thus operationalize the spatial matrix by adopting a row-normalized matrix where $w_{i j}=1$ if local government $j$ is among the $k$ nearest neighbours of local government $i$, where $k$ is the number of nearest neighbours. Following LeSage and Pace (2009: Chapter 6) we select the appropriate $k$ by estimating models based on varying numbers of nearest neighbours and then we compute the models’ Bayesian posterior probabilities, with higher probabilities reflecting superior model fit.

It should be noted, however, that similarities between local governments leading to isomorphic mechanisms may arise from forces besides geographical distance. In particular, some authors have stressed the importance of ideological similarity, suggesting that the 
diffusion effect of policy adoption by one government will be greatest on nearby governments sharing the ideological preferences of an adopter (e.g. Grossback et al., 2004). We explored this possibility by constructing a spatial matrix where wij=1 if two local governments shared a ruling party (Conservative, Labour or Liberal Democrat), but found no evidence of spatial dependence using this ideological weighting matrix (available on request), adding further confidence in our selection of a geographical spatial matrix.

\section{Study Context}

The dataset has been collected from English local governments. These are elected bodies, with a Westminster-style cabinet system of political management, which is usually made up of senior members of the ruling political party. English local governments receive approximately two-thirds of their income from the central government, and so their decisionmaking is heavily influenced by national level policy and regulatory frameworks. In terms of service delivery, they are multi-purpose authorities delivering services education, social care, land-use planning, waste management, public housing, leisure and culture, and welfare benefits. In 2007, there were 386 local governments of five types. 32 London boroughs, 36 metropolitan boroughs, and 46 unitary authorities mostly in urban areas delivering all of the services listed above; and in rural areas 34 county councils administering education and social services, and 238 district councils providing housing, leisure and cultural services.

We investigate contracting out of public leisure provision, which is a service that appropriately reflects the emergence of a mixed economy of service delivery, where public agencies are increasingly seen to contract out parts of their services to other providers. For the purposes of our analysis, we focus on the year 2007 as this was the final year in which the Best Value regime was fully operational, and so represents the culmination of nearly two decades of regulatory effort to encourage English local governments to consider contracting 
services out and to compare themselves with their neighbouring authorities. In this respect, we are able to capture institutional influences on contracting behaviour in a way in which it has not been possible to do following the replacement of Best Value with a more informal regulatory regime. Because we focus on contracting out of local leisure services, county councils are not included in a sample of 335 local governments that due to missing data also omits a small number of district councils.

In 2007, approximately $1 \%$ of the local government annual budget ( $£ 1$ billion) was spent on providing sports facilities, such as leisure centres, swimming pools and playing fields to the local community. This is roughly the same as the money spent on libraries and is equivalent to about half the money spent on waste management services. It is a service for which there is a large market of potential external providers and is indicative of those public sector services that face increasing prominence of external agencies (private and not-forprofit) entering the sector to capitalize on opportunities in service delivery (Hodgkinson and Hughes 2014). Information regarding local governments’ contracting of service provision was obtained from The Leisure Database Company (TLDCi) for 2007. This database contains information about the management model of each facility run by all the local governments in England (i.e. in-house, commercial firm, not-for-profit provider).

\section{Dependent Variables}

As previously stated, the dependent variable in equation 3 takes a value of 1 if the local government decides to contract out and 0 for in-house delivery. Almost $81 \%$ of English local governments use only one delivery form for their leisure service provision (in-house, commercial firm or not-for-profit provider), with the remaining 19\% using a combination of these methods. A local government with a mixed management model is considered to be a 'contractor' if over $50 \%$ of its facilities were managed by external contractors. In equation 4 , 
the dependent variable takes a value of 1 if the local government provides the service through a commercial firm(s), and 0 if the service is delivered through a not-for-profit provider(s). 9.4\% of the 'contractor' sample use a combination of both methods, so we consider a local government as a 'privatizer' if over $50 \%$ of the facilities were managed by commercial firms.

The spatial distribution of contracting out versus in-house service delivery is shown in Figure 1A, with geographical clustering (or spatial dependence) evident in London and the South East of England. There is also evidence of spatial dependence in the Bristol area, the Manchester area and in the local governments bordering Scotland. Figure 1B shows the spatial distribution of commercial firms versus not-for-profit providers. Though it seems there are some geographical clusters in contracting with not-for-profit providers, particularly in the North and South East of England, the spatial association among observations for privatisation is not as clear as for the decision to contract out.

[Figure 1 about here]

\section{Contracting Determinants}

The $\mathrm{X}_{\mathrm{i}}$ matrix includes a set of local ideological, political and economic factors that may influence the adoption of contracting out policies. Our source of data on these variables is a compilation of publications (e.g. Department of Communities and Local Government 2008; Office for National Statistics 2003; Office of the Deputy Prime Minister 2002; 2003; Rallings and Thrasher 2003; 2007). Since our empirical approach does not allow all of the explanatory variables to be measured at the time the decision regarding the management of each service facility was taken, we take averaged values of several explanatory variables for 2000-2007 or for the closest election/census year. 
To evaluate the influence of ideology when implementing contracting policies, we include in our model a dummy variable which takes a value of 1 if the Labour party holds the local government or controls a majority of the cabinet posts in 2007 - a figure all but constant from 2000 (details available on request). The prediction is that left majorities will make use of contracting and/or private firms to a lesser extent than right majorities.

As regards politics, five measures are selected to gauge whether the choices of local policy-makers might be influenced by citizens’ preferences about the size and role of government: first, we measure the averaged percentage share of the vote gained by the Labour Party in the local elections between 2001 and 2007. Local residents voting Labour are expected to have a 'collectivist' disposition favouring in-house or non-private forms of service delivery (see Clarke et al. 2004). Second, we include the total local government expenditure per capita, averaged between 2001 and 2007 to gauge local residents preferences for the role of government; in municipalities with higher service needs (and therefore higher expenditure), local residents may be less likely to support privatization (Kodrzycki 1994; Brudney et al. 2005). Finally, more vulnerable citizens are thought to favour government provision of public services, particularly low income citizens and ethnic minorities (Brudney et al. 2005). To account for this, we measure the rate of deprivation within the local population averaged between 2000 and 2007, and two dimensions of the diversity of service needs: ethnic and social class diversity. The proportions of the different ethnic and social subgroups within the local population (e.g. Indian and Routine Occupations) identified in the 2001 UK national census was squared, and the sum of the squares was subtracted from 10,000, with a higher level of diversity reflected in a higher score.

To control for economic influences on contracting out decisions three variables are selected. First, the degree of competition among potential service providers is measured using a dichotomous variable coded 1 for those governments serving urban populations and 0 for 
those serving rural populations. This variable was based on the urban-rural administrative area classification used by UK central government (see Office of the Deputy Prime Minister 2002). Second, we include the population of municipalities to test whether economies of scale influence the contracting out decision. Urban indices and population figures have been extensively used in the empirical literature on contracting out (Bel and Fageda 2007, 2009). In addition, we also consider the possibility that population growth could overload the service delivery capacity of local governments, leading them to use contracting to meet increased demand (Brudney et al. 2005). To account for this overload effect we include in our model a variable measuring population growth based on census data. Descriptive statistics for all the variables used in our models are reported in Table 1.

[Table 1 about here]

\section{RESULTS}

From a Bayesian perspective, statistical inference can be derived from an analysis of the posterior distribution, which can be approximated using curve estimation methods. Thus, figures 2 and 3 show the posterior densities of the coefficient estimates for both models, approximated by kernel density estimation based on the bandwidth rule of thumb proposed by Silverman (1986). In order to further facilitate the interpretation of results we also present a numerical summary of the posterior, i.e. posterior means and standard deviations in table 2, along with Bayesian p-levels, for the statistical models. These measure whether the coefficient is sufficiently different from zero. Following LeSage and Pace (2009), this statistic, though contrary to Bayesian convention, should be comparable to the conventional p-level associated with the t-statistic from the non-spatial probit models (see also Gelman et al. 1995). MCMC sampling procedures for both equations are based on 10000 draws with the first 1000 draws excluded to account for the burn-in period of the sampler. The 
estimations were computed in Matlab using James LeSage’s spatial econometrics toolbox, downloaded from www.spatial-econometrics.com, May 2014. Estimations computed with 2000 and 5000 draws and different burn-in periods gave basically the same results.

The number of steps for the Gibbs sampler has been set to 10, which is standard for Bayesian probit approaches. We set the prior hyperparameter to 4, which reflects a prior belief in heteroskedasticity (LeSage and Pace 2009). In addition to the discussed Bayesian approach to SAR probit models, we report standard probit estimates ignoring spatial policy dependence to benchmark the robustness of the results to different model specifications.

\section{The Contracting Out Decision}

The first objective of this empirical analysis is to test the factors influencing the decision to contract out service provision. Regarding ideology, the results suggest that local governments with a Labour majority are no more likely to contract out than those local governments with Conservative or Liberal Democrat majorities, which might be interpreted as a sign of policy convergence on the decision to contract out. Our findings also suggest that citizens' preferences and economic factors are not affecting the choice between contracting out or inhouse provision. On the other hand, the posterior mean of the spatial lag coefficient $(\rho)$ is positive (0.39) and the posterior density is clearly centred away from zero which, along with the reported Bayesian p-level (0.012), strongly suggests the presence of spatial dependencies among the neighbouring local governments. The evidence of positive spatial dependence means that the decision to contract out (or keep in-house) in local government $i$ appears to be influencing that decision in a neighbour local government $j$. This result, alongside the lack of statistical significance for the other explanatory variables, suggests that institutional isomorphism is at work in shaping local governments' decision-making. 
The importance of mimetic pressures when explaining contracting out might be a consequence, in our context, of the regulatory regime faced by English local governments. Central government encouraged local governments to avoid in-house provision of services if a more efficient provider or management model existed, with serious consequences if authorities failed to challenge existing models of provision and compare themselves with other organizations. Hence, coercive and mimetic institutional forces may well be operating in tandem in this instance. That said, in a scenario of uncertainty about outcomes, it is conceivable that mimetic forces alone may explain the adoption of management practices for which there is insufficient empirical evidence of performance benefits (Ashworth et al. 2009). Or, put differently, for some local governments the safest strategy for resolving the 'make or buy?' decision may simply be to emulate the policy adopted by one’s neighbour, especially given the wider institutional forces indicating that contracting out is "the right thing to do". While our findings are strongly suggestive of spatial dependence in the contracting behaviour of English local governments, further research is required to determine the precise interplay between the different institutional forces shaping the decision-making of councils. In-depth case studies in the service departments of local governments could, for example, highlight the extent to which the decision to adopt the practices of their neighbours is driven by coercive and/or normative pressures.

[Figure 2 about here]

[Table 2 about here]

\section{Commercial Firm or Not-for-profit Provider?}

The estimation of the equation explaining the factors influencing the choice of service contractor offers a completely different picture to the equation modelling the decision to 
contract out. Now, we find no evidence of spatial dependence. Although the posterior mean for $\rho$ takes a positive value (about 0.25 ), a relatively large fraction of the posterior mass takes negative values which, along with the reported Bayesian p-level (0.132), do not permit us to clearly conclude that $\rho$ is greater than zero. This suggests that local governments make the decision to sign a contract with either a private firm or a not-for-profit provider independently of the choices of their neighbours. With respect to the ideology variable, we find no evidence that local governments led by the Labour party are more reluctant to contract with commercial firms than not-for-profit providers: the coefficient for Labour majority is negative, as expected, but not statistically significant. In this line, the coefficient for total service expenditure is also negative as expected but, again, not statistically significant. By contrast, local residents' political preferences seem to be an important determinant of the choice of contractor - the posterior mean for Labour votes is negative and centred away from zero.

Local governments with higher Labour vote shares appear to be more likely to contract with not-for-profit providers than with commercial firms, which points towards the responsiveness of local governments to the views of local residents. Contrary to much of the extant literature this suggests that the contracting choices of local policy-makers are more likely to be influenced by public opinion than by the ideology of the party that they represent. In line with previous studies, our findings also indicate that urban local governments are more likely to contract with commercial firms (Warner and Hefetz 2003) - the posterior mean for the urban variable is positive and centred away from zero. This may be due to the larger number of potential bidders in urban areas, but also because commercial firms are more likely to provide the service in urban areas where, a priori, there might be a larger number of potential customers. In line with this finding, the posterior mean for population growth is also positive and centred away from zero. This anticipated higher market share, 
therefore, may attract a larger number of commercial firms (Girth et al. 2012) Overall, it is evident from the findings that once the decision to contract out has been taken, there remain important political and economic influences at play that ultimately impact the outcome of the ‘buy’ decision (i.e. whether contracting-out to commercial firms or not-for-profit providers). Again, further qualitative research could cast light on the ways in which noneconomic motives shape contracting decisions.

[Figure 3 about here]

\section{CONCLUSIONS}

In this paper, we have analysed the determinants of contracting out in a competitive public service setting in English local governments, supplementing the focus on ideological and political influences in prior studies with an emphasis on institutional influences. In doing so, we utilise a spatial auto-regressive probit model to capture patterns of policy diffusion attributable to coercive and mimetic pressures towards institutional isomorphism. Our findings suggest that institutional factors play an important role in shaping the contracting out decision, but that the choice of contractor is driven by political and economic considerations. There is evidence of spatial dependence in the decision to contract out service provision in English local governments, and evidence that local governments serving populations with a 'collectivist' disposition prefer to contract with not-for-profit providers rather than commercial firms. These findings have important theoretical and practical implications.

Firstly, we provide strong statistical evidence that the decision-making of public organizations may be the product of institutional isomorphism. Contracting out decisions, in particular, may not simply reflect the imperatives of the technical operating environment, but be the result of forces within the institutional environment. We have been able to illustrate 
patterns of institutional isomorphism by utilising spatial statistical techniques. Nevertheless, recent developments in new institutional theory point towards the importance of the "logics" that shape the decisions of key stakeholder groups (Dunn and Jones 2010) and the role played by institutional entrepreneurs in "making things happen” (Tracey, Phillips and Jarvis 2011). Future quantitative and qualitative studies of the institutional influences on the behaviour of public organizations should therefore seek to analyse the extent to which isomorphism may reflect the operation of wider professional logics - amongst contract managers or those managers working within discrete policy fields such as leisure services, for example. It would also be valuable to investigate the extent to which "entrepreneurial” decision-makers take their cues from the management practices of neighbouring organizations and the institutional work they undertake to “sell” mimesis to internal stakeholders.

Secondly, our study confirms the insights of the policy diffusion literature regarding the salience of geographical proximity for public policy implementation. It is therefore essential to consider spatial dependence in models of local government contracting, and that institutional influences may explain the presence of geographical clustering of organizational behaviour. Mimesis driven by uncertainty, especially, may be particularly important when understanding of the relationship between practice and performance is unclear; such as is the case in leisure provision (Audit Commission 2006). Thus, future studies of the decisionmaking of public service organizations should always seek to ascertain whether there are spatial patterns reflected in geographical proximity and driven by institutional pressures.

Thirdly, our study suggests that politics may determine the choice of contractor selected by local governments, even though it may not influence the decision to contract out. Wherever possible, subsequent research should aim to establish the relative salience of institutional, ideological and political influences on whether local governments choose to contract with the private or not-for-profit sector once the decision to contract out has been 
taken. There are other local public service markets in England (and elsewhere) that exhibit the kind of supplier diversity that facilitates the more in-depth analysis of contracting behaviour that we undertake here. Contracting out of elderly care services, in particular, also involves a wide range of private and not-for-profit providers and accounts for vast sums of money in the UK local government system (Bode 2006). Evidence on the determinants of contracting in this service would therefore cast valuable further light on this important issue.

Despite the strengths of our analysis, there are a number of limitations in our study design, which provide opportunities for further research. First, although we offer a rare test of spatial dependence in contracting out decisions, we draw upon a cross-sectional dataset that does not enable us to fully tease out the causal effects of changes in institutional, ideological and political influences on contracting behaviour. Unfortunately, due to commercial confidentiality restrictions it was not possible for us to measure management type on an annual basis on this occasion. Panel data incorporating information on annual expenditure on contractors and on the award of new contracts and the termination of old ones would undoubtedly enable the role of geographical proximity in contracting behaviour to be investigated in even more depth.

Second, our study examines contracting out at a time when regulatory pressure on local governments to consider contracting services out was particularly strong. It would be interesting to undertake a similar study in circumstances where regulatory pressure was more diffuse, and public organizations' benchmarking less defensive. Thirdly, it is possible that unmeasured confounders correlated with geographical distance could be responsible for our results. For example, personnel movements between neighbouring local governments may influence contracting out decisions, and spillover effects related to supplier availability and competitiveness may be important. While the effects of personnel movements on contracting are difficult to measure, and the inclusion of an urban/rural variable may capture supplier 
spillover effects, more research is required to tease out the causal mechanisms fully, especially in-depth case studies involving interviews with key actors. Finally, the 2000's were a time of fiscal plenty in the English local government system, and it is quite conceivable that the determinants of contracting out may differ in the wake of the severe budget cuts carried out in the past few years.

In sum, our study has highlighted the role that institutional factors play in shaping decision-making in the public sector, identifying isomorphic pressures that underpin the decision to contract services out. It has also illustrated the potential for other non-economic motives to influence the choice of contractor. Further research comparing the importance of institutional and non-economic motives for contracting out and for the choice of contractor would add vital knowledge on the forces that shape decision-making in public organizations.

\section{ACKNOWLEDGEMENT}

The authors would like to thank Vanesa Jordá for her useful methodological comments and suggestions.

\section{REFERENCES}

Alonso, J. M., J. Clifton and D. Díaz-Fuentes. 2015. 'Did New Public Management Matter? An Empirical Analysis of the Outsourcing and Decentralization Effects on Public Sector Size’, Public Management Review, 17, 5, 643-660.

Ammons, D.N. and D.J. Roenigk. 2015. 'Benchmarking and Interorganizational Learning in Local Government', Journal of Public Administration Research and Theory, 25, 1, 309335. 
Ashworth, R., G.A. Boyne and R. Delbridge. 2009. 'Escape from the Iron Cage? Organizational Change and Isomorphic Pressures in the Public Sector', Journal of Public Administration Research and Theory, 19, 165-87.

Audit Commission. 2006. Public Sports and Recreation Services: Making Them Fit for the Future. Audit Commission for Local Authorities and the National Health Service in England.

Baekkskov, E. 2011. 'Issue Framing and Sector Character as Critical Parameters for Government Contracting-out in the UK’, Public Administration, 89, 4, 1489-1508.

Beck, N., K.S. Gleditsch and K. Beardsley. 2006. 'Space is more than Geography: Using Spatial Econometrics in the Study of Political Economy', International Studies Quarterly, 50, $27-44$

Bel, G. and X. Fageda. 2009. 'Factors Explaining Local Privatization: A Meta-regression Analysis’, Public Choice, 139, 105-19.

Bel, G. and X. Fageda. 2007. 'Why do Local Governments Privatise Public Services? A Survey of Empirical Studies’, Local Government Studies, 33, 517-34.

Bel, G. and M.E. Warner. 2008. 'Challenging Issues in Local Privatization', Environment and Planning C: Government and Policy, 26, 104-09.

Berry, F.S., and Berry, W.D. 1999. Innovation and Diffusion Models in Policy Research. In P. Sabatier (ed) Theories of the policy process. Colorado: Westview Press.

Bivand, R. and S. Szymansky. 2000. 'Modelling the Spatial Impact of the Introduction of Compulsory Competitive Tendering', Regional Science and Urban Economics, 30, 20319.

Bode, I. 2006. 'Co-governance within Networks and the Non-profit/for-profit Divide: A Cross-cultural Perspective on the Evolution of Domiciliary Elderly Care', Public Management Review, 8, 551-66. 
Bowerman, M., A. Ball and G. Francis. 2001. 'Benchmarking as a Tool for the Modernisation of Local Government', Financial Accountability \& Management, 17, 32129.

Brudney, J.L., S. Fernandez, J.E. Ryu and D.S. Wright. 2005. 'Exploring and Explaining Contracting Out: Patterns among the American States', Journal of Public Administration Research and Theory, 15, 393-419.

Brueckner, J.K. 1998. 'Strategic Interaction among Governments: The Case of Growth Controls’, Journal of Urban Economics, 44, 438-67.

Clarke, H.D., D. Sanders, M.C. Stewart and P. Whiteley. 2004. Political Choice in Britain. Oxford: Oxford University Press.

Department of Communities and Local Government (DCLG). 2008. The English Indices of Deprivation 2007. DCLG: London.

DiMaggio, P.J. and W.W. Powell. 1983. 'The Iron Cage Revisited: Institutional Isomorphism and Collective Rationality in Organizational Fields', American Sociological Review, 48 147-60.

Domberger, S. and P. Jensen. 1997. 'Contracting Out by the Public Sector: Theory, Evidence, Prospects’, Oxford Review of Economic Policy, 13, 67-78.

Dunn, M.B. and C. Jones (2010) 'Institutional Logics and Institutional Pluralism: The Contestation of Care and Science Logics in Medical Education, 1967-2005', Administrative Science Quarterly, 55, 1, 114-149.

Elhorst, J.P. 2009. 'Spatial Panel Data Models', in M.M. Fischer and A. Getis (eds) Handbook of Applied Spatial Analysis: Software Tools, Methods and Applications. Berlin: Springer, 377-408.

Elinder, M. and H. Jordahl. 2013. 'Political Preferences and Public Sector Outsourcing', European Journal of Political Economy, 30, 43-57. 
Entwistle, T. 2011. 'For Appropriateness or Consequences: Explaining Organizational Change in English Local Government’, Public Administration, 89, 661-80.

Foster, D. and P. Scott. 1998. 'Conceptualising Union Responses to Contracting Out Municipal Services, 1979-97’, Industrial Relations Journal, 29, 137-50.

Gelman, A., J.B. Carlin, H.S. Stern and D.B Rubin. 1995. Bayesian Data Analysis. New York: Chapman and Hall.

Girth, A.M., A. Hefetz, J.M. Johnston and M.E. Warner. 2012. 'Outsourcing Public Service Delivery: Management Responses in Noncompetitive Markets', Public Administration Review, 72, 887-900.

Gramlich, E.M. and D.L. Rubinfeld. 1982. 'Micro Estimates of Public Spending Demand Functions and Tests of the Tiebout and Median-voter Hypotheses', Journal of Political Economy, 90, 536-60.

Grossback, L. J., S. Nicholson-Crotty and D.A. Peterson. 2004. 'Ideology and Learning in Policy Diffusion’, American Politics Research, 32, 521-545.

Gulick, L. and L. Urwick (eds). (1937) Papers on the Science of Administration. New York: Columbia University.

Hefetz, A. and M.E. Warner. 2003. 'Rural-urban Differences in Privatisation: Limits to the Competitive State', Environment and Planning C: Government and Policy, 21, 703-18.

Hefetz, A., M.E. Warner and E. Vigoda-Gadot. 2012. 'Privatisation and Intermunicipal Contracting: The US Local Government Experience, 1992-2007’, Environment and Planning C: Government and Policy, 30, 675-92.

Hodgkinson, I.R. and P. Hughes. 2014. 'Strategy Content and Public Service Provider Performance in the UK: An Alternative Approach', Public Administration, 92, 3, 707726. 
LeSage, J.P. and R.K. Pace. 2009. Introduction to Spatial Econometrics. Boca Raton, FL: CRC press.

LeSage, J.P. 2000. 'Bayesian Estimation of Limited Dependent Variable Spatial Autoregressive Models’, Geographical Analysis, 32, 19-35.

Liao, T. 1994. Interpreting Probability Models: Logit, Probit, and Other Generalized Linear Models. Sage.

Kodrzycki, Y.K. 1994. 'Privatization of Local Public Services: Lessons for New England', New England Economic Review, May, 31-46.

Martin, S.J. 2000. 'Implementing 'Best Value’: Local Public Services in Transition’, Public Administration, 78, 209-27.

Matten, D. and J. Moon. 2008. ““Implicit” and “Explicit” CSR: A Conceptual Framework for a Comparative Understanding of Corporate Social Responsibility.', Academy of Management Review, 33, 404-24.

Mooney, C. Z., and M.H. Lee. 1995. 'Legislative Morality in the American states: The Case of Pre-Roe Abortion Regulation Reform', American Journal of Political Science, 39, 3, 599-627.

Office of the Deputy Prime Minister (ODPM). 2002. Urban and Rural Area Definitions: A User Guide. London: ODPM.

ODPM. 2004. The English Indices of Deprivation 2004. London: ODPM.

Office for National Statistics (ONS). 2003. Census 2001, National Report for England and Wales. London: ONS.

Osborne, M.J. and A. Slivinski. 1996. 'A Model of Political Competition with CitizenCandidates', Quarterly Journal of Economics, 111, 65-96.

Picazo-Tadeo, A.J., F. González-Gómez, J.G. Wanden-Berghe and A. Ruiz-Villaverde. 2012. 'Do Ideological and Political Motives Really Matter in the Public Choice of Local 
Services Management? Evidence from Urban Water Services in Spain’, Public Choice, 151, 215-28.

Rallings, C. and M. Thrasher. 2003. Local Elections in Britain: A Statistical Digest. LGC Elections Centre, University of Plymouth.

Rallings, C. and M. Thrasher. 2007. Local Elections Handbook 2007. LGC Elections Centre, University of Plymouth.

Rincke, J. 2006. 'Policy Innovation in Local Jurisdictions: Testing for Neighborhood Influence in School Choice Policies’, Public Choice, 129, 189-200.

Schmitt, C. 2014. 'The Diffusion of Privatization in Europe: Political Affinity or Economic Competition?’, Public Administration (ahead-of-print) 1-21

Scott, W.R. 2014. Institutions and Organizations: Ideas, Interests and Identities, $4^{\text {th }}$ ed. London: Sage

Shipan, C. R., and C. Volden. 2012. 'Policy Diffusion: Seven Lessons for Scholars and Practitioners', Public Administration Review, 72, 788-796.

Silverman, B. 1986. Density Estimation for Statistics and Data Analysis. Chapman \& Hall: London.

Simon, H.A. (1976) Administrative Behavior: A Study of Decision-making Processes in Administrative Organization, 3rd ed, Macmillan: London.

Smith, M.J. 2010. 'From Big Government to Big Society: Changing the State-society Balance', Parliamentary Affairs, 63, 818-33.

Sundell, A. and V. Lapuente. 2012. 'Adam Smith or Machiavelli? Political Incentives for Contracting out Local Public Services’, Public Choice, 153, 469-85.

Tiebout, C. 1956. 'A Pure Theory of Local Expenditure’, Journal of Political Economy, 64, 5, 416-24. 
Tobler, W. 1970. 'A Computer Movie Simulating Urban Growth in the Detroit Region', Economic Geography, 46, 234-40.

Tracey, P., N. Phillips and O. Jarvis. 2011. 'Bridging Institutional Entrepreneurship and the Creation of New Organizational Forms: A Multilevel Model’, Organization Science, 22, $1,60-80$.

Villadsen, A.R. 2013. 'Similarity or Difference? The Relation Between Structure and Strategy Isomorphism in Public Organizations’, British Journal of Management, 24, S62S75.

Villadsen, A.R., J.R. Hansen and N.P. Mols. 2010. 'When do Public Managers Imitate each Other? Mimetic Decision Making in Contracting Decisions of Danish Municipalities', Public Organization Review, 10, 357-376.

Zafra-Gómez, J.L., D. Prior, A.M. Plata-Díaz and A.M. López-Hernández. 2013. 'Reducing Costs in Times of Crisis: Delivery Forms in Small and Medium-sized Local Governments’ Waste Management Services’, Public Administration, 91, 51-68. 
Table 1 Descriptive statistics

\begin{tabular}{lcccc}
\hline Variable & \multicolumn{2}{c}{ All districts } & $(335)$ & \multicolumn{2}{c}{ Districts contracting out (170) } \\
\cline { 2 - 5 } & Mean & SD & Mean & SD \\
\hline Contracting out & 0.507 & 0.501 & - & - \\
Commercial firm & - & - & 0.453 & 0.499 \\
Labour majority & 0.069 & 0.253 & 0.065 & 0.247 \\
Labour votes & 25.524 & 14.017 & 24.665 & 14.196 \\
Log (service spend) & 5.676 & 1.081 & 5.709 & 1.099 \\
Deprivation & 20.979 & 10.134 & 20.315 & 10.393 \\
Social class diversity & 8762.87 & 117.48 & 8768.51 & 102.42 \\
$\begin{array}{l}\text { Ethnic diversity } \\
\text { Urban }\end{array}$ & 1656.794 & 1723.917 & 1959.812 & 1987.716 \\
Log (population) & 0.597 & 0.491 & 0.600 & 0.491 \\
Population growth & 11.715 & 0.527 & 11.720 & 0.487 \\
\hline $\begin{array}{l}\text { Note: } \text { To deal with non-normal distributions of the variables measuring population and service needs we use their logged } \\
\text { values in the regression models. }\end{array}$ & & & & \\
\hline
\end{tabular}


Table 2 Probit estimates of the choice of management model for public leisure services

\begin{tabular}{|c|c|c|c|c|c|c|c|c|c|c|c|c|}
\hline & \multicolumn{6}{|c|}{ Contracting out vs In-house } & \multicolumn{6}{|c|}{ Commercial firm vs not-for-profit } \\
\hline & \multicolumn{3}{|c|}{ Probit model } & \multicolumn{3}{|c|}{ SAR Probit model } & \multicolumn{3}{|c|}{ Probit model } & \multicolumn{3}{|c|}{ SAR Probit model } \\
\hline & Coeff. & S.E. & p-level & $\begin{array}{l}\text { Post. } \\
\text { Mean }\end{array}$ & $\begin{array}{l}\text { Posterior } \\
\text { SD }\end{array}$ & p-level & Coeff. & S.E. & p-level & $\begin{array}{l}\text { Post. } \\
\text { Mean }\end{array}$ & $\begin{array}{l}\text { Posterior } \\
\text { SD }\end{array}$ & p-level \\
\hline Labour majority & -0.028 & 0.294 & 0.925 & 0.180 & 0.243 & 0.230 & -0.136 & 0.490 & 0.781 & -0.435 & 0.409 & 0.142 \\
\hline Labour votes & -0.005 & 0.007 & 0.513 & -0.006 & 0.008 & 0.218 & -0.025 & 0.012 & 0.036 & -0.020 & 0.012 & 0.056 \\
\hline $\begin{array}{l}\text { log(spending per } \\
\text { capita) }\end{array}$ & 0.035 & 0.117 & 0.765 & 0.021 & 0.117 & 0.427 & -0.111 & 0.190 & 0.560 & -0.081 & 0.191 & 0.330 \\
\hline Deprivation rate & -0.010 & 0.011 & 0.342 & -0.007 & 0.010 & 0.257 & -0.014 & 0.015 & 0.369 & -0.007 & 0.017 & 0.329 \\
\hline Social class diversity & 0.000 & 0.001 & 0.827 & 0.000 & 0.001 & 0.334 & -0.001 & 0.001 & 0.333 & -0.001 & 0.001 & 0.090 \\
\hline Ethnic diversity & 0.000 & 0.000 & 0.001 & 0.000 & 0.000 & 0.014 & -0.000 & 0.000 & 0.401 & 0.000 & 0.000 & 0.231 \\
\hline Urban & 0.017 & 0.185 & 0.927 & -0.012 & 0.186 & 0.477 & 0.566 & 0.284 & 0.047 & 0.530 & 0.291 & 0.034 \\
\hline $\log ($ population) & -0.168 & 0.199 & 0.399 & -0.139 & 0.199 & 0.245 & 0.188 & 0.338 & 0.579 & 0.135 & 0.336 & 0.345 \\
\hline Population growth & 0.088 & 0.094 & 0.347 & 0.085 & 0.095 & 0.187 & 0.232 & 0.135 & 0.087 & 0.188 & 0.141 & 0.091 \\
\hline Spatial lag $(\rho)$ & & & & 0.390 & 0.151 & 0.012 & & & & 0.249 & 0.226 & 0.132 \\
\hline Log Likelihood & -222.77 & & & & & & -104.23 & & & & & \\
\hline Estimation Method & ML & & & MCMC & & & ML & & & MCMC & & \\
\hline Observations & 335 & & & 335 & & & 170 & & & 170 & & \\
\hline
\end{tabular}

Notes: To operationalize the spatial weighting matrix, the Bayesian posterior probabilities point to a model with 17 nearest neighbours for the full sample and 15 nearest neighbours in the case of those municipalities contracting out. 

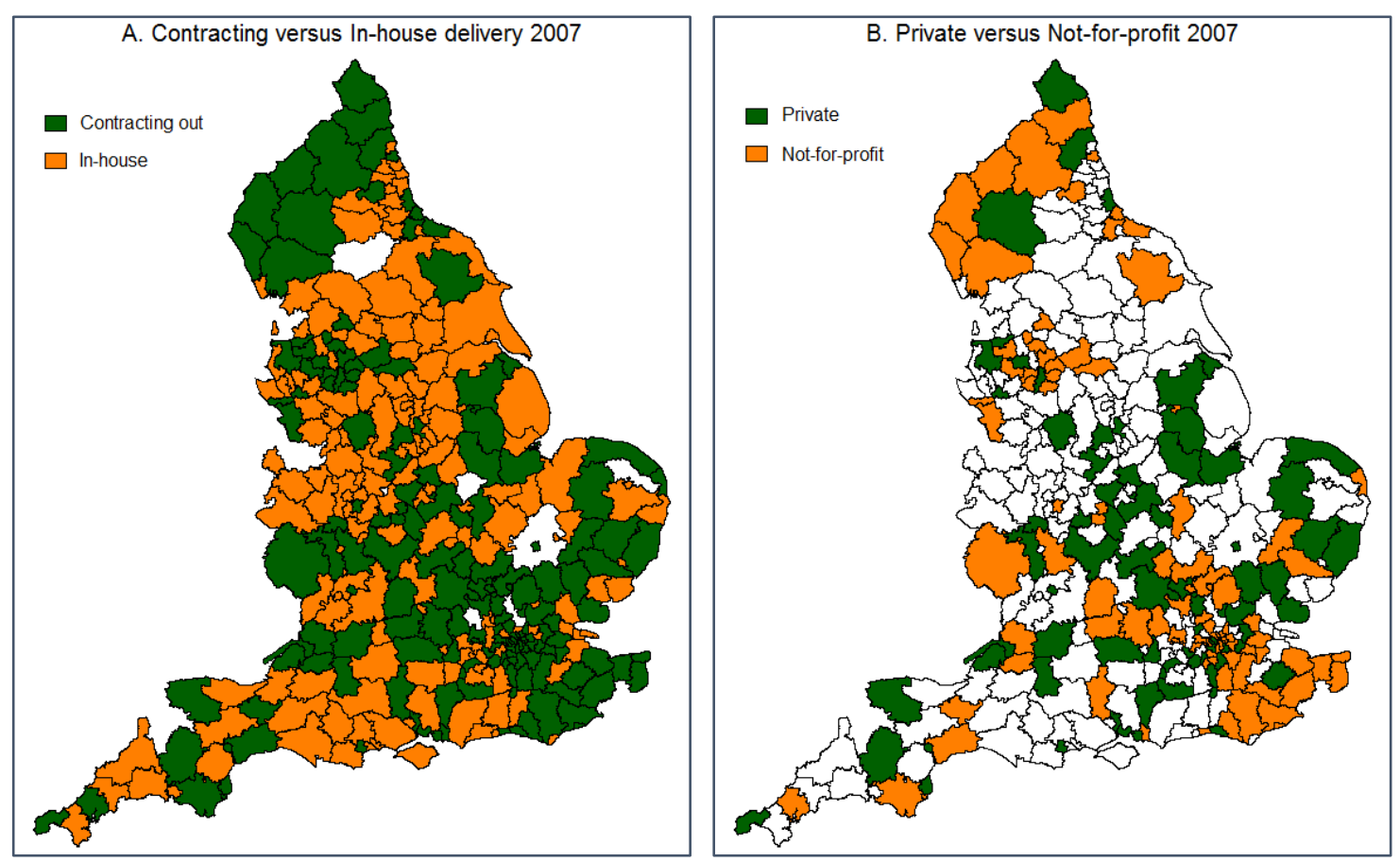

Figure 1 English local governments’ leisure service provision, 2007 

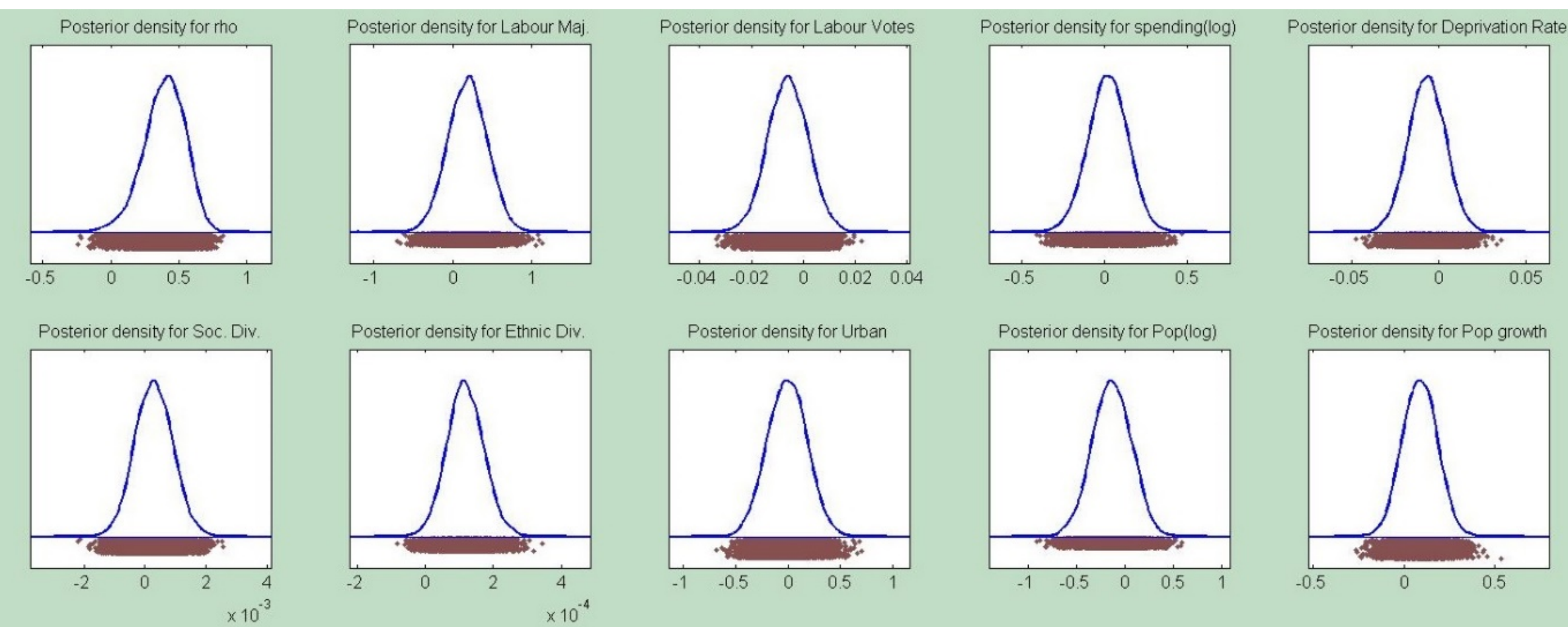

Posterior density for Pop(log)

Posterior density for Pop growth
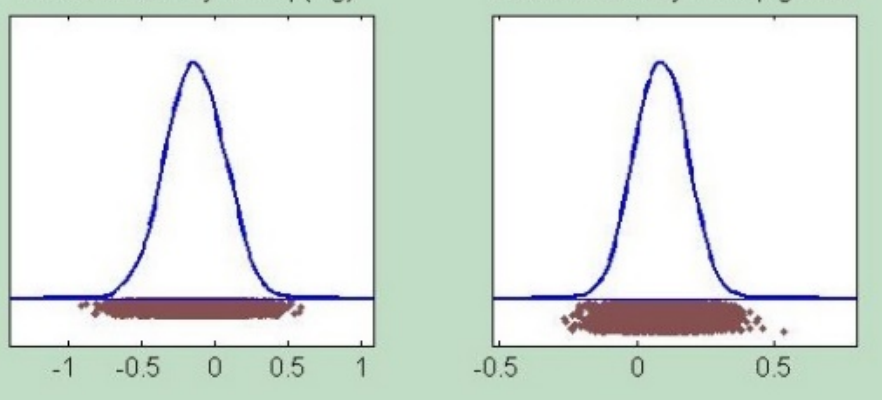

Figure 2 Posterior densities for contracting $v s$ in-house. 

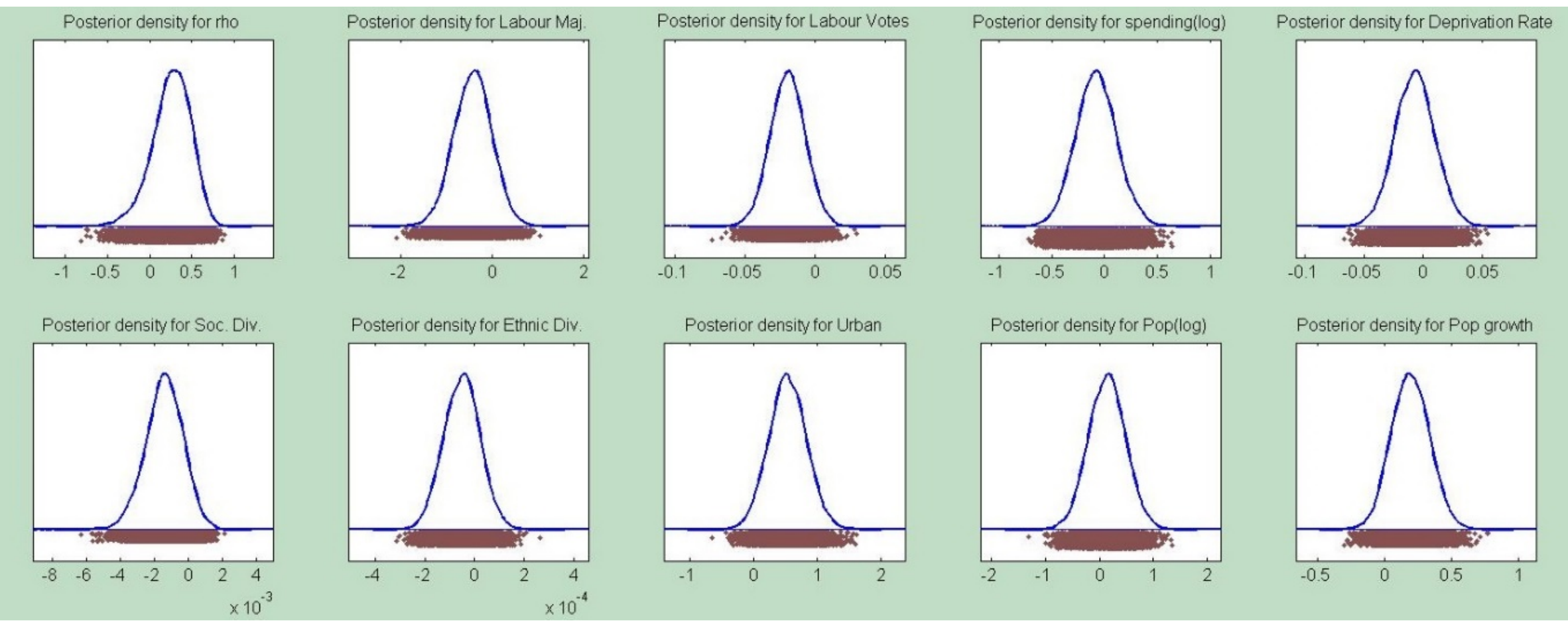

Figure 3 Posterior densities for commercial firm vs not-for-profit. 